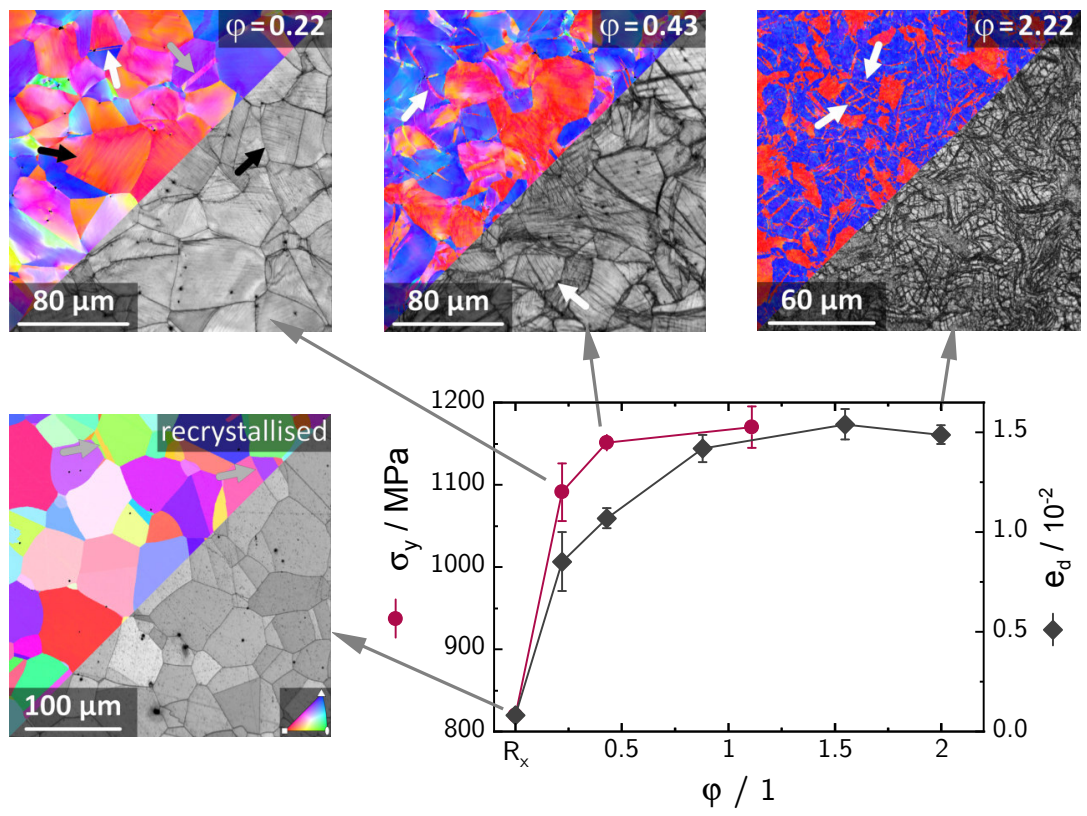

M. Motylenko D. Rafaja

Graphical Abstract

Origins of strength and plasticity in the precious metal based HighEntropy Alloy AuCuNiPdPt

F. Thiel, D. Geissler, K. Nielsch, A. Kauffmann, S. Seils, M. Heilmaier, D. Utt, K. Albe, neu, neu, J. Freudenberger 


\section{Highlights}

Origins of strength and plasticity in the precious metal based HighEntropy Alloy AuCuNiPdPt

F. Thiel, D. Geissler, K. Nielsch, A. Kauffmann, S. Seils, M. Heilmaier, D. Utt, K. Albe, neu, neu, J. Freudenberger

- The precious metal based High-Entropy Alloy (HEA) AuCuNiPdPt is of single phase fcc structure in the homogenised state.

- Decomposition occurs during annealing AuCuNiPdPt at intermediate temperatures.

- $\mathrm{AuCuNiPdPt}$ deforms by deformation twinning and dislocation slip at room temperature.

- AuCuNiPdPt shows a high yield strength of $820 \mathrm{MPa}$ and a high yield ratio of 0.66 at room temperature as well as significant strain hardening during deformation.

- The strengthening mechanisms of AuCuNiPdPt are assessed. 


\title{
Origins of strength and plasticity in the precious metal based High-Entropy Alloy AuCuNiPdPt
}

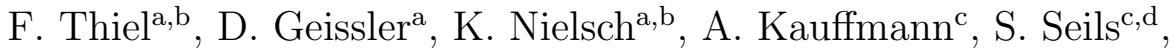 \\ M. Heilmaier ${ }^{\mathrm{c}}$, D. Utt ${ }^{\mathrm{e}}, \mathrm{K} . \mathrm{Albe}^{\mathrm{e}}, \mathrm{neu}^{\mathrm{f}}$, neu ${ }^{\mathrm{f}}$, J. Freudenberger $^{\mathrm{a}, \mathrm{f}, *}$ \\ ${ }^{a}$ Leibniz IFW Dresden, Institute for Metallic Materials (IMW), Helmholtzstraße 20, \\ D-01069 Dresden, Germany \\ ${ }^{b}$ TU Dresden, Institute of Materials Science, D-01062 Dresden, Germany \\ ${ }^{c}$ Karlsruhe Institute of Technology (KIT), Institute for Applied Materials (IAM-WK), \\ Engelbert-Arnold-Straße 4, D-76131 Karlsruhe, Germany \\ ${ }^{d}$ Karlsruhe Institute of Technology (KIT), Karlsruhe Nano Micro Facility (KNMF), \\ Hermann-von-Helmholtz-Platz 1, D-76344 Eggenstein-Leopoldshafen, Germany \\ ${ }^{e}$ TU Darmstadt, Institut für Materialwissenschaft, Otto-Berndt-Str. 3, D-64287 \\ Darmstadt, Germany \\ ${ }^{f}$ TU Bergakademie Freiberg, Institute of Materials Science, Gustav-Zeuner-Straße 5, \\ D-09599 Freiberg, Germany
}

\begin{abstract}
The precious metal based High-Entropy Alloy (HEA) AuCuNiPdPt crystallises in a face-centred cubic structure and is single phase without chemical ordering after homogenisation. However, a decomposition is observed after annealing at intermediate temperatures. This HEA shows extended malleability during cold work up to a logarithmic deformation degree of $\varphi=2.42$. The yield strength ranges from $820 \mathrm{MPa}$ in the recrystallised state to $1170 \mathrm{MPa}$ when strain hardened by cold working with a logarithmic deformation degree of $\varphi>0.6$. This work hardening behaviour is traced back to a steep increase in dislocation density as well as in deformation twinning occurring at low strain. The microstructure and the mechanical properties of $\mathrm{AuCuNiPdPt}$ are assessed in detail by various methods. EBSD and TEM analyses reveal mechanical twinning as an important deformation mechanism. The high strength in the recrystallised state is evaluated and found to originate predominantly upon solid solution strengthening.
\end{abstract}

\footnotetext{
${ }^{*}$ Corresponding author.

Email address: j.freudenberger@ifw-dresden.de (J. Freudenberger)
} 
Keywords: high-entropy alloy, solid solution, microstructure, deformation twinning, plasticity

\section{Introduction}

Solid-solutions with multi-element compositions have been investigated for decades, e.g. in austenitic steels [1-5]. Nevertheless, the introduction of High-Entropy Alloys (HEA) stimulated extensive research since these multiprincipal element alloys differ significantly from conventional alloys, whose design is based on a strategy that considers one principal element, only. Despite the original definition, HEAs are nowadays defined as multi-component single phase alloys with at least five elements of which each of them has an alloy content of 5 at.\% or above [6]. In particular, the multi-component alloys with an equiatomic composition represent HEAs in which no element possesses majority. It has been discovered by chance that some of these equiatomic alloys crystallise in a single phase crystal structure $[6,7]$. Their single phase nature clearly separates high-entropy alloys from compositionally complex alloys (CCA), which have similar compositions but are multiphase alloys [8]. Moreover, HEAs show properties such as a combination of high strength and high ductility, which would not have been expected for conventional intermetallic phases comprising similar stoichiometries [9-11].

Research in the field of HEAs allows for gaining a fundamental understanding of composition determined materials properties, such as solid solution hardening, diffusion mechanisms as well as temperature dependence of deformation behaviour. To comprise this large area, experimental studies as well as novel modelling approaches are required. Consequently, one key question is how the conventional models for solid solution strengthening that consider matrix and solute elements, will have to be modified if no matrix element can be assigned. To address this question, HEAs are required that (i) crystallise as homogeneous solid solution and (ii) exhibit a wide range of stoichiometries with identical crystal structure. In addition, further parameters that determine the strength such as grain size and dislocation density have to be at the similar level.

With the AuCuNiPdPt system, a new strategy to find HEAs that addresses the aforementioned criteria is presented. This strategy is focussed on evaluating the binary phase diagrams with respect to a solubility within the entire concentration range. Furthermore, five elements are seeked for, 
which show this homogeneous solid solution for any of the ten binary phase diagrams. Although a number of practically single-phase HEAs has been discovered under appropriate processing conditions, such as $\mathrm{CoCrFeMnNi}$ (face-centred cubic, fcc) [7], AuCuNiPdPt (fcc) [12], AlCoCrFeNi (bodycentred cubic, bcc) [13], HfNbTaTiZr (bcc) [14], MoNbTaVW (bcc) [15], and DyGdHoTbY (hexagonal closed packed, hcp) [16], the concentration range between the quinary alloys and their subsystems in which the alloys are single-phase can be limited. According to the present literature, the AuCuNiPdPt appears to be the only fcc-type HEA, in which the solid solution might be expected within the entire concentration range [12]. Although there is no experimental proof for this statement, there are reasons for indirect evidence. Firstly, the known binary and ternary subsystems show singlephase solidification within the entire concentration range [17]. Secondly, even though ordered phases or miscibility gaps are observed in some phase diagrams at low temperatures, there is no evidence of intermetallic phases close to the solidus line. Thirdly, it has been shown, that the equiatomic quaternary subsystems as well as the quinary HEA crystallise in the fcc single-phase Cu-type structure [12]. In principle, this strategy of seeking for solid solutions within the subsystems would also work for the HfNbTaTiZr (bcc) [14] and MoNbTaVW (bcc) [15] HEAs. However, these systems have not been reported to be found by this strategy.

The mechanical properties of fcc HEAs were predominantly investigated for $\mathrm{CoCrFeMnNi}$ and its derivatives, since this was the first reported HEA [7]. Furthermore, this alloy is easy to process by casting and various deformation techniques, even in larger dimensions. The homogenised and quenched fcc phase appears stable at room temperature [18]. However, this alloy exhibits a metastable behaviour at elevated temperatures showing inhomogeneities and short-range ordering [19-21]. The tensile properties and microstructure of CoCrFeMnNi have been widely investigated [10, 20, 22, 23]. Plasticity is dominated by dislocation slip at room temperature. However, twinning is observed after a considerable amount of true strain but still below the ultimate tensile strength (UTS) in the range of uniform elongation. Consequently, during strain hardening the critical resolved shear stress required for twinning has been reached at room temperature [22]. In contrast, twinning is activated at lower strains, when testing at cryogenic temperatures was performed. Even though, $\varepsilon$-martensite formation was not found $(<77 \mathrm{~K})$ $[10,22,24]$. While the contribution of mechanical twinning to the total plastic strain is low, twinning causes significant strain hardening [24]. This is 
also associated to the formation of nanoscaled twins [25] which has a strong influence on a sound determination of the grain size. CoCrFeMnNi shows a dependence of the hardness on the grain size following the Hall-Petch relationship [10, 26]. However, the Hall-Petch coefficient is larger when compared to non HEA fcc alloys. The yield strength of CoCrFeMnNi amounts to approx. $300 \mathrm{MPa}$ at room temperature while the uniform elongation attributed to this measurement is approx. $40 \%$ [25]. It has been observed, that both values increase when lowering the temperature at which the tensile test is carried out [10, 24, 25].

The present article aims at providing an in-depth analysis of the microstructural evolution as well as the mechanical properties of AuCuNiPdPt during heat treatments and cold work. Much effort has been put into a precise production of the alloy with well-defined homogeneity. The metallurgical conception of $\mathrm{AuCuNiPdPt}$ provides the basis for the investigation of the evolution of the microstructure as well as of the mechanical properties in the fcc $\mathrm{Cu}$-type crystal structure that are dependent on the composition in a wide concentration range.

\section{Experimental}

Polycrystalline samples of AuCuNiPdPt were prepared from pure elements (Au: 4N, Allgemeine Gold- und Silberscheideanstalt AG (AGOSI); Cu: 5N5, VEB Spurenmetalle Freiberg/Sa.; Ni: 4N, Alfa Aesar; Pd: 3N5, AGOSI; Pt: 4N, AGOSI). The elements were weighed according to the desired composition. For alloying, the metals were placed in an arc melter (Edmund Buehler $\mathrm{GmbH}$ ) on a water-cooled copper hearth, while the high melting point elements were placed on top. Melting was performed with a maximum current of 200 A to minimise evaporation losses; no significant mass losses were detected. In order to enhance the homogeneity, the ingot was flipped over and re-melted four times. Each melting step lasts for $30 \mathrm{~s}$. The surface of the melt looked homogeneous while melting. While the melt was cooled down as ingot in the first melting steps, the last melting step was completed by suction casting into a water-cooled copper mould of $6 \mathrm{~mm}$ in diameter and $90 \mathrm{~mm}$ in length. The total mass was overestimated by $30 \%$ for dense casting. The additional material was sectioned prior to further processing.

The as-cast alloys were homogenised at $1100{ }^{\circ} \mathrm{C}$ for $20 \mathrm{~h}$ in protective Argon atmosphere with subsequent water-quenching. For this purpose, 
the samples were placed in fused silica ampoules, which were evacuated to $<10^{-3}$ mbar and back-filled with Ar three times. Before sealing, the Ar pressure within the ampoules was set to 22 mbar in order to achieve atmospheric pressure within the ampoules at the chosen annealing temperature. The ampoules were destroyed to allow for rapid water-quenching.

The homogenised sample was cold worked at room temperature by rotary swaging (UR2-4, Heinrich Müller Maschinenfabrik, Pforzheim) with an area reduction per step of approximately $20 \%$ and a total logarithmic degree of deformation of $\varphi=0.64\left(\varphi=\ln \left(A_{i} / A_{f}\right)\right.$, where $A_{i}$ and $A_{f}$ are the initial and final cross sectional area, respectively). The semi-cone angle of the tools was $6^{\circ}$. After deformation, the samples were heat treated at $1100{ }^{\circ} \mathrm{C}$ for $1 \mathrm{~h}$ in order to obtain a fully recrystallised microstructure. Annealing was performed in sealed fused silica ampoules with subsequent water-quenching as described before. Afterwards, the sample was further cold worked by rotary swaging up to a total logarithmic degree of deformation of $\varphi=2.42$. For the evaluation of the Hall-Petch hardening, AuCuNiPdPt samples were recrystallised for different times, i.e. $2.5 \mathrm{~min}, 5 \mathrm{~min}, 1 \mathrm{~h}$ and $65 \mathrm{~h}$, respectively. While the short annealings were performed in air atmosphere, the long annealings were performed in sealed fuzed-silica ampoules as described before. All samples were placed in the hot furnace and subsequently quenched in ice-water.

Structural characterisation by XRD was done on bulk samples utilising a STOE STADI_P diffractometer with $\mathrm{MoK}_{\alpha 1}$ radiation $(0.70932 \mathrm{~nm})$ in transmission geometry equipped with a position sensitive detector (PSD) Dectris Mythen $1 \mathrm{~K}$ and a curved Ge(111)-monochromator (step size $\Delta 2 \theta=$ $\left.0.01^{\circ}\right)$.

For microstructural analysis and hardness tests, the samples were embedded in a non-conductive epoxy resin and prepared by a conventional metallographic procedure, which includes grinding on abrasive $\mathrm{SiC}$ paper up to a grid size of P4000, polishing on MD-Mol and MD-Nap cloths (Struers) using diamond suspension (MetaDi Supreme suspension, Buehler) with a net particle size of $3 \mu \mathrm{m}, 1 \mu \mathrm{m}$ and $0.25 \mu \mathrm{m}$, respectively. To remove the residual surface-near deformation layer, etching with diluted aqua regia $\left(25 \% \mathrm{H}_{2} \mathrm{O}\right)$ was applied for $30 \mathrm{~s}-60 \mathrm{~s}$. Samples for transmission electron microscopy (TEM) analyses were extracted from the metallographically prepared samples with the help of the focussed ion beam (FIB) technique utilising an FEI Helios 600i.

Microstructural characterisation was carried out by scanning electron microscopy (SEM) using an FEI Helios 600i. At the same device, electron 
backscatter diffraction (EBSD) measurements were done at $20 \mathrm{kV}$ operating voltage and $11 \mathrm{nA}$ probe current using an EDAX DigiView system. TEM analysis was performed utilising a Jeol JEM 2200 FS system operated at $200 \mathrm{kV}$. The microscope is equipped with a field emission gun (FEG), a Cs-corrector for the illumination system, a high-resolution objective lens $(\mathrm{Cs}=0,5 \mathrm{~mm})$ and a highly sensitive $2 \mathrm{Kx} 2 \mathrm{~K}$ CCD camera of Gatan. The investigation was performed by high resolution TEM (HRTEM) and analyzed by means of Fast Fourier Transformation (FFT), to carry out the local orientation.

Microhardness measurements were performed on 15 indentations utilising a Shimadzu HMV-2 hardness tester at a load of 1.98 N. Compressive tests were performed at RT on samples with an initial height of $\lesssim 6 \mathrm{~mm}$, which is equivalent to an aspect ratio of $\mathrm{h}_{0} / \mathrm{d}_{0} \lesssim 2$. The tests were stopped when the aspect ratio approached $\mathrm{h}_{0} / \mathrm{d}_{0}=1$. Tensile tests were performed on samples with a diameter of $2.4 \mathrm{~mm}$ within the gauge section. The gauge length was $25 \mathrm{~mm}$. The strain was measured with the help of a laser extensometer. For mechanical tests an electro-mechanical Instron 5869 testing machine was used with a constant crosshead movement corresponding to an initial engineering strain rate of $\dot{\varepsilon}=1 \cdot 10^{-3} \mathrm{~s}^{-1}$.

Atom probe tomography (APT) was utilised to evaluate uniform element distribution after recrystallisation. The investigated sample was entirely prepared from grain volume without any grain boundaries with a FIB FEI Strata utilising the standard lift-out method on a microtip coupon [27, 28]. The analysis was performed with a local electrode atom probe (LEAP 4000X $\mathrm{HR}$, Cameca) at a temperature of about $50 \mathrm{~K}$ with a pulse frequency of $125 \mathrm{kHz}$ and a pulse energy of $50 \mathrm{pJ}$. The reconstructed tip consisted of ap-

proximately $13 \cdot 10^{6}$ ions. For the evaluation of the APT results, the Cameca software IVAS 3.6.14 was used.

\section{Results and discussion}

\subsection{Preparation of single-phase $A u C u N i P d P t$}

The AuCuNiPdPt HEA shows significant segregations in the as-cast state as can be seen from the dendritic microstructure in Fig. 1(a). These fluctuations show regions reduced in $\mathrm{Ni}$ and $\mathrm{Pt}$ and enriched in $\mathrm{Au}, \mathrm{Cu}$ and $\mathrm{Pd}$ (and vice versa) with a compositional deviation of about \pm 10 at.\%. The variations in concentration vanish as a result of appropriate heat treatments. When the 
as-cast sample is homogenised at $1100{ }^{\circ} \mathrm{C}$ for $20 \mathrm{~h}$ and subsequently waterquenched, the microstructure is homogeneous and single-phase, as shown in Fig. 1(b). Further evidence for the single-phase nature of the homogenised sample is provided by X-ray diffraction analysis. Fig. 2 shows the diffraction pattern of the homogenised AuCuNiPdPt sample. There are no indications in the diffraction pattern for secondary phases or ordering phenomena.

However, the temperature of homogenisation heat treatment has to be chosen appropriately. When the samples are heat treated at lower temperatures but still for the same period of $20 \mathrm{~h}$ and subsequently water-quenched, phase separation occurs, which is more pronounced at lower temperature. When $\mathrm{AuCuNiPdPt}$ is heat treated at e.g. $800{ }^{\circ} \mathrm{C}$, two fcc phases occur, as can be seen from the splitting of the (111) reflection of the diffraction pattern. The microstructure of this state is shown in Fig. 3 in combination with the elemental distribution maps, that were determined by using energy dispersive X-ray spectroscopy (EDX). This provides evidence that the phase formation is not a precipitation reaction, but follows a decomposition. Regarding the EDX maps in Fig. 3(b) to Fig. 3(f) the microstructure is decomposed in a Ni- and Pt-rich phase (black arrow in Fig 3(a)) and a Au-, $\mathrm{Pd}$ - and Cu-rich (white arrow in Fig 3(a)) phase. Since this multi-component alloy is rather complex, the appearance of the phases is not steady in stoichiometry, but shows small variations in concentration within the respective phase areas, depending on the temperature and time of the heat treatment. Tab. 1 reflects the elemental compositions of the two phases as revealed by EDX point analysis, which were performed at representative positions as indicated by the arrows in Fig. 3(a). This behaviour has been observed earlier for $\mathrm{AuCuNiPt}$ [12] and explained by a preferential pairing of particular elements. For example, the binary Ni-Pt bonds are favoured according to the enthalpies of mixing of the binary systems, while Au-Ni bonds are unlikely. This is a further indication for the complexity of phase formation and decomposition in HEAs especially at low temperatures, which solely cannot be easily attributed to the amount of configurational entropy of mixing [29, 30]. In fact, as the contribution of the configurational entropy to the Gibbs free energy is scaled by temperature, it is not surprising that the influence of mixing entropy to stabilise the solid solution looses importance with decreasing temperature. Hence, the enthalpy of mixing must not be neglected as a significant parameter to the Gibbs free energy. Consequently, the enthalpy of mixing determines whether the alloy decomposes into multiple phases or if it remains a homogeneous solid solution especially at low temperatures. 
Increasing the temperature of isothermal annealing for $20 \mathrm{~h}$ and subsequent water-quenching causes these two phases to dissolve. On the level of EDX spatial resolution no segregations can be observed anymore. Consequently, the splitting of reflections in XRD pattern and, thus, the difference in composition is less pronounced. It should be noted, that the lattice parameter in the $\mathrm{AuCuNiPdPt}$ system is a direct measure of the stoichiometry [12]. Annealing the sample at $900{ }^{\circ} \mathrm{C}$ still causes segregation in two phases as can be seen in Fig. 2. The according lattice parameters are $0.3811 \mathrm{~nm}$ and $0.3819 \mathrm{~nm}$. These values are much closer to each other than those obtained for the phases in the sample annealed at $800{ }^{\circ} \mathrm{C}$ (lattice parameters: $0.3775 \mathrm{~nm}$ and $0.3869 \mathrm{~nm}$ ). This means that the deviation of the lattice parameters of the two phases decreases from $2.4 \%$ to $0.22 \%$ when increasing the annealing temperature from $800{ }^{\circ} \mathrm{C}$ to $900{ }^{\circ} \mathrm{C}$. When the temperature of the heat treatment is set to $1000{ }^{\circ} \mathrm{C}$, it is not possible anymore to determine two distinct lattice parameters. However, the segregation is still apparent in the peak broadening (Fig. 2).

When the AuCuNiPdPt phase is homogenised at $1100{ }^{\circ} \mathrm{C}$ no segregations can be detected from XRD. This temperature is close to the melting temperature of the alloy $\left(T_{S}=1196{ }^{\circ} \mathrm{C}[31]\right)$. This provides evidence that the temperature range between the solidus line and initiation of phase separation, in which this alloy can be homogenised, is rather narrow. Hence, a subsequent water-quenching after annealing is absolutely essential in order to keep the alloy in the single-phase state.

Although the composition of solid solutions generally define their properties, it is of importance to determine whether the properties are defined exclusively upon the global composition or if these are also affected by local variations of the composition. To prove or to disprove this issue, it is necessary to evaluate the composition at the local scale. Therefore, atom probe tomography has been employed to provide chemical information at the atomic length scale. The results of the APT measurement are summarised in Fig. 4. The determined chemical composition of the entire tip is provided in Tab. 3. The three-dimensional elemental distributions, shown in Figs. 4(a), appear homogeneous. For the sake of clarity only $3 \%$ of all ions of an element are visualised here. The total concentration in the APT tip after deconvolution of overlapping peaks indicates a near-equiatomic composition, as the EDX results do. The concentration profile along the cylinder indicated in Fig. 4(b) and taken in direction of the black arrow reveals no significant variation in the concentration when a step size of $1 \mathrm{~nm}$ is applied. To exclude the possible 
formation of inhomogeneities like nanoscaled clusters a frequency distribution analysis is performed by virtually cutting the tip in equisized voxels of 100 ions each. If no clustering occurs, a binomial distribution of the concentration in the voxels is expected as it is obtained in Fig. 4(c). In this case, the Pearson coefficient $\mu$, explained in detail elsewhere [28, 32] and quantifying the deviation between binomial and experimental distribution, is close to 0 . In the present analysis $\mu \leq 0.07$ is obtained for all elements from which a homogeneous elemental distribution can be assumed (see Tab. 3). Nevertheless, it has to be noted that all quantification methods average over several unit cells and, hence, possible ordering in superlattice structures cannot be unambiguously excluded by APT measurements.

\subsection{Microstructural evolution during cold work of AuCuNiPdPt}

\subsubsection{Texture evolution}

The homogenised and single-phase AuCuNiPdPt alloy was subjected to cold work. First of all, this was performed in order to obtain a homogeneous and well-defined microstructure with a uniform grain size suitable for further evaluation. This requires subsequent recrystallisation. For this purpose, the $\mathrm{AuCuNiPdPt}$ alloy was cold worked by rotary swaging up to a logarithmic degree of deformation of $\varphi=0.6$. The sample was subsequently heat treated for static recrystallisation. As lower temperatures yield phase separation, the temperature was set to $1100{ }^{\circ} \mathrm{C}$. This heat treatment was carried out for $1 \mathrm{~h}$ with subsequent water-quenching. The resulting microstructure is shown in Fig. 5(a). The microstructure, obtained by electron backscatter diffraction (EBSD) with the corresponding image quality (IQ) maps, is composed of equiaxed grains with an average grain size of about $50 \mu \mathrm{m}$ and with an almost random orientation distribution (Fig. 5(e)). In addition, as can be seen from the IQ maps, there are few pores originating from suction casting of the sample.

Samples in the recrystallised state having a diameter of $4.35 \mathrm{~mm}$ were further cold worked by rotary swaging with an areal reduction of approximately $\varphi=0.22$ per step. Cold working has been applied up to $\varphi=2.42$ (diameter of the wires: $1.30 \mathrm{~mm}$ ). The alloy can be subjected to significant cold work, but the heating during cold work is substantial. Therefore, the alloy was cooled to room temperature after each deformation step. The deformation causes the initial state to develop towards a mixture of $\langle 111\rangle /\langle 001\rangle$ fibre components with a dominating $\langle 111\rangle$-fibre. This development towards a double fibre texture shows similar behaviour like what has been observed for 
conventional fcc alloys such as Cu-based alloys [33] or austenitic FeMn-base TWIP-alloy [5]. The evolution of the texture is seen from the orientation maps (Figs. 5(b) to 5(d)) as well as the inverse pole figures (IPF, Figs. 5(e) to $5(\mathrm{~h}))$. At $\varphi=0.43$, the $\langle 111\rangle$-fibre component exhibits an intensity of about $6 \mathrm{~m}$.u.d. (multiples of the uniform distribution) which increases to about $20 \mathrm{~m}$. u. d. at the maximum applied degree of deformation.

\subsubsection{Strain localisation and deformation twinning}

In the initial condition and after the first deformation step $(\varphi=0.22)$, recrystallisation twins are apparent in the microstructure, as highlighted by grey arrows in Fig 5(a). In analogy to texture evolution with respect to Ref. [5, 33], mechanical twinning is initiated by plastic deformation highlighted by white arrows in Fig. 5(c) and 5(d). Besides dislocation slip, this mechanical twinning or TWIP-effect apparently contributes to the plastic deformation of the presently investigated HEA. The orientation of the deformation twins corresponds to approximately $\langle 115\rangle$-fibre orientations (indicated by the magenta colour in the EBSD maps), which is the ideal orientation resulting from twinning in a $\langle 111\rangle$-oriented grain. The IQ map represents a measure for the local defect density. Within this image, twins are seen in a more pronounced way. However, not all twins are correctly identified by the help of orientation mapping. This is mainly attributed to overlapping Kikuchi patterns, caused by the size of microstructural features. Hence, some of the defects shown in Fig. 5(b) might also originate from small-scaled deformation twins, as e.g. the area pointed at by the white arrow. This indicates, that nucleation of deformation twinning starts at a deformation strain just below $\varphi=0.22$. Even though, cold work was imposed by rotary swaging, a clear orientation dependence of deformation twinning is seen

from Fig. 5. The preference for near $\langle 111\rangle$-fibre oriented grains is basically the same as in the case of tensile tests [5, 24] or wire drawing [33] of low stacking fault energy (SFE) alloys implying a similar shear stress state for rotary swaging. Despite the fact that close to $\langle 001\rangle$ oriented grains are not likely to twin, the extended stacking faults in low SFE alloys still and generally lead to a propensity to planar glide or slip band formation, i.e. localised deformation [34]. This is depicted by the grains marked with a black arrow in Fig. 5(b). Though having unfavourable orientation for deformation twinning, these grains have minor stripe-like orientation variations (also IQcontrast stripes in other grains as seen from Fig. 5), which are interpreted as slip bands. Extended stacking faults or nucleation of single partial dislo- 
cations from grain boundaries are widely accepted to be the most plausible initiation sites for deformation twinning [5, 35, 36].

For better visibility, Fig. 6(a) shows mechanical twinning (white arrows) as well as disordered arrangements of extended stacking faults, i.e. slip bands (black arrow) mapped with a higher resolution. Similar results were obtained in Refs. [37, 38]. Although slip bands cannot be indexed by EBSD, the reduced IQ-level compared to the diffraction signal of the matrix leads to a clear distinction. The corresponding IQ-Map in combination with the kernel average misorientation (KAM) map is depicted in Fig. 6(b). KAM analysis is a measure for the local misorientation assigned to a centre point of a particular grain with respect to all points in the perimeter of the kernel [39]. Due to this analysis, localised strain within single grains becomes visible, which can bee seen in this case close to grain boundaries, deformation twins and slip bands. Further, the strain concentration in the vicinity of slip bands due to localised deformation is obviously independent from the grain orientation. Even though, the localisation of slip strikingly coincides with the arrangement of deformation twins identified beyond all doubt in the later stages of deformation only near $\langle 111\rangle$ oriented grains. Hence, this is a direct evidence for the aforementioned coherence between the slip bands and deformation twinning in this HEA. Because deformation twinning is geometrically not feasible in grains with $\langle 001\rangle$ orientation [40], further cold work leads to a severely strained lattice with an increased misorientation within grains as shown in Fig. 5(c) and 5(d).

Based on the previous findings, it appears evident that the formation of deformation twins represents an active deformation mechanism in the $\mathrm{AuCu}-$ NiPdPt high-entropy alloy. For deeper analysis of size and arrangement of deformation twins and stacking faults, high-resolution TEM and fast Fourier transform was applied. For this purpose a lamella, perpendicular to the twin boundaries, was prepared by FIB subsequent to EBSD analysis from the selected grain shown in Fig. 6(a). Fig. 7 shows the twin at a magnification of approx. 250k (7(a)) and 600k (7(b)) as well as a fast Fourier transform (7(c)) of a selected area covering matrix and twin across a single twin boundary (indicated by an arrow in Fig. 7(a)). The primary beam direction close to [1 $\overline{1} 0]$ allows for a local analysis of the depicted twin boundary $(111) /(11 \overline{1})$. As indicated in Fig. 7(c) the bright spots correspond to reflections that arise either from the twin, or from the matrix. Although the twins shown in Fig. 7(a) occur with different widths, common values are in the nanometre range, i.e. the twin shown in Fig. 7(a) has a width of $11 \mathrm{~nm}$. 


\subsubsection{Grain refinement}

The microstructure in the recrystallised state is governed by equiaxed grains with a mean grain size of about $50 \mu \mathrm{m}$. By applying cold work via rotary swaging, the aspect ratio of the grains changes due to geometrical necessity regarding the volume conservation. Thus, the grain size is reduced transverse and extended parallel to the wire axis. Moreover, deformation twinning in $\langle 111\rangle$ oriented grains creates further grain boundaries resulting in substantial grain refinement. The evolution of the grain size distribution as well as the mean grain diameter in cross section as a function of the logarithmic degree of deformation is shown in Fig. 8. Due to the aforementioned mechanisms a steep decrease in grain size transverse to the wire axis is apparent. From the perspective of the mechanical characterisation, the grain size in cross section is more relevant when loading the sample along the wire axis, because dislocation motion in fcc metals occurs on $\{111\}\langle 110\rangle$ glide systems. At $\varphi \geq 0.43$ the microstructure is dominated by $\langle 111\rangle$ oriented grains intersected by thin lamellae of a few micrometre in width (see Fig. 5(c) and 5(d)). As the deformation strain which can be achieved by twinning is limited, the twins are further deformed by dislocation slip during continuing cold work. As a consequence of deformation, the orientation of the twins rotates into the direction of $\langle 001\rangle$ which causes an increasing amount of high-angle grain boundaries at later stages of deformation. The minimum grain diameter in cross section is about $10 \mu \mathrm{m}$. Since deformation twinning occurs predominantly in $\langle 111\rangle$ oriented grains, a bimodal microstructure is observed. Original matrix grains with a close to $\langle 001\rangle$ fibre orientation remain typically stable upon uniaxial elongation by deformation, such as tension, wire drawing and rotary swaging. All intermediate orientations close to $\langle 011\rangle$ and $\langle 111\rangle$ tend to rotate towards $\langle 111\rangle$ in the course of this type of deformation. Consequently, there is a gradient in deformation twin density. Thus, a difference in grain size is observed between grains that start to deform from orientations close to $\langle 111\rangle$ in contrast to grains which rotate towards these orientations where deformation twinning is favourable. In summary, the microstructure consists of comparably large grains with $\langle 001\rangle$ orientation and a majority of $\langle 111\rangle$-oriented grains intersected by thin lamellae with $\langle 001\rangle$ orientation as well. This leads to the large grain size distribution as seen from Fig. 8. 


\subsubsection{Williamson-Hall analysis}

The aforementioned lattice strain caused by deformation twinning and dislocation accumulation is further analysed by XRD. Unfortunately, it is difficult to quantify the density of lattice imperfections. However, the WilliamsonHall analysis provides the apparent mean lattice strain $\left\langle\varepsilon_{h k l}^{2}\right\rangle^{\frac{1}{2}}$ of a sample by analysing the line broadening in XRD pattern [41]. The dependence of the line broadening on the diffraction angle $\theta$ is determined by:

$$
F W H M=\frac{K}{\langle D\rangle}+\frac{4}{\lambda} \sqrt{\left\langle\varepsilon_{h k l}^{2}\right\rangle} \sin \theta
$$

where FWHM, i.e. full width of the diffraction peak at half maximum, is the physical line broadening, $\langle D\rangle$ is the mean crystallite size, $K$ a factor concerning the crystallite shape $(K=0.94$ for cubes [42]) and $\lambda$ the wavelength of the radiation. Within the Williamson-Hall analysis, represented by a $F W H M-\sin \theta$ plot, a linear dependence is observed, analysing the line broadening of reflections $h k l$ referred to the diffraction angle. Consequently,

$\frac{K}{\langle D\rangle}$ represents the intersection with the y-axis, while $\frac{4}{\lambda} \sqrt{\left\langle\varepsilon_{h k l}^{2}\right\rangle}$ is the slope of the straight line. The latter serves as the base of calculating the mean lattice strain.

In the case of deforming a single phase polycrystalline alloy, the dislocation density represents the main contribution to the line broadening. For this HEA there is also an additional contribution from extended stacking faults and stacking fault arrangements [43]. However, in the present case of intense plastic deformation this is a minor contribution and will not be considered here in detail.

In most crystals, the ane broadening is anisotropic, i.e., it depends on the crystallographic direction. In the HEA under investigation, this anisotropy has been described by the cubic invariant $\Gamma=\left(h^{2} k^{2}+k^{2} l^{2}+h^{2} l^{2}\right) /\left(h^{2}+k^{2}+\right.$ $\left.l^{2}\right)^{2}[44,45]$. Considering elastic anisotropy of the crystal, Eq. 1 is reassessed using the modified Williamson-Hall plot [44-48]:

$$
F W H M=\frac{K}{\langle D\rangle}+4 \sqrt{\left\langle\varepsilon_{100}^{2}\right\rangle(1-\zeta \Gamma)} \frac{\sin \theta}{\lambda},
$$

where $\sqrt{\left\langle\varepsilon_{100}^{2}\right\rangle(1-\zeta \Gamma)}$ is defined as the resulting lattice strain recalculated into the easy deformation direction of $\langle 100\rangle$ in cubic crystals corrected by the cubic invariant $\Gamma$ as well as the anisotropic part of the line broadening $\zeta[46,47]$. 
The peak widths (FWHM) were determined by single profile fitting on XRD patterns from incrementally pre-deformed samples by means of rotary swaging. The aforementioned modified Williamson-Hall analysis was performed as shown exemplarily for $\varphi=0.43$ in the inset of Fig. 9. As can be seen, the fitting procedure yields a reasonable correlation factor of the fit as far as the very weak 400 reflection is not considered within the evaluation. This appears reasonable since the intensity of this reflection is rather low and no reliable fitting was possible for most of the samples under investigation.

Since the size of coherently scattering regions exceeds an evaluable limit, the crystallite size is not considered in the further analysis but used as a supporting point for the linear regression. The mean lattice strain $\left\langle\varepsilon_{100}^{2}\right\rangle$ commonly defined by the variation of the inter-planar spacing $d$, i.e. $e_{d}=$ $\sqrt{\left\langle(\Delta d / d)^{2}\right\rangle}$ is assigned to the slope of the modified Williamson-Hall plot by utilisation of Eq. 2. The resulting mean lattice strain in dependence on the logarithmic degree of deformation is seen from Fig. 9. The evaluation revealed an apparent lattice strain of $(0.08 \pm 0.02) \cdot 10^{-2}$ for the recrystallised condition. This is obvious when regarding the annealed microstructure without any residual lattice strain from prior deformation. After subsequent cold work a rapid increase is observed leading to a lattice strain of $(1.07 \pm 0.05) \cdot 10^{-2}$ for $\varphi=0.43$. The apparent lattice strain saturates at $(1.50 \pm 0.10) \cdot 10^{-2}$ for a logarithmic deformation degree larger than $\varphi=1$. This behaviour is in good agreement with the microstructural analysis shown in Fig. 5 and common for the strain response after cold work of fcc metals and alloys leading to a saturation at an intermediate logarithmic degree of deformation.

\subsection{Mechanical properties}

\subsubsection{Examination of the strength}

The mechanical properties of AuCuNiPdPt are assessed by compression and hardness testing after every step of cold working. The results, i.e. the true stress-strain curves, as well as the corresponding yield strength and Vickers microhardness as a function of the logarithmic degree of deformation are depicted in Fig. 10(a) and Fig. 10(b), respectively. In the recrystallised state, AuCuNiPdPt shows a compressive yield strength of $820 \mathrm{MPa}$ and a hardness of $345 \mathrm{HV} 0.2$. The true stress strain curve reveals significant work hardening, which reaches saturation at a true strain of $\varepsilon=0.40$. This is in good accordance with results from hardness testing after recrystallisation and 
subsequent cold work using rotary swaging, which saturates at a similar level of strain. In addition, hardness values during cold work after homogenisation are presented, showing essentially the same behaviour.

The yield strength was determined from three samples, which were tested in each condition. The obtained individual strength values show the same behaviour, while the arising deviations are reflected by the error bars, shown in Fig. 10(b). The preceding cold work strengthens the alloy and, consequently, the yield strength increases with increasing degree of cold work. With increasing degree of cold work prior to testing, the strain hardening during mechanical testing becomes less pronounced and saturation is immediately reached beyond yield strength. This also becomes evident when considering the microstructural results in the previous sections. Firstly, as can be seen from Figs. 5, the evolution of the texture is rapid and apparently has been developed to its final texture components within $\varphi=0.4$. Secondly, the evolution of lattice defects also saturates within this level of deformation as can be seen from Fig. 9, where the apparent lattice strain is plotted as a function of the logarithmic degree of deformation. Thirdly, the decreasing grain size with proceeding cold work (see Fig. 8) has obviously a minor contribution on the mechanical strength.

To complement the evaluation of the recrystallised state, samples of $\mathrm{Au}-$ $\mathrm{CuNiPdPt}$ were also tested under tensile loading conditions. Fig. 11 shows the corresponding true stress-strain curve. The yield strength was determined to be $830 \mathrm{MPa}$, which is in good agreement with the value obtained from compression tests. The ultimate tensile strength amounts to $1200 \mathrm{MPa}$. Further, the alloy shows significant ductility in the tensile test, i.e. a true plastic strain of 0.14 is observed. Work hardening in tension is similar, when compared to the compression tests. In addition, the work hardening rates are similar as well, as depicted in the insert of Fig. 11.

\subsubsection{Assessment of the strengthening mechanisms}

The different strengthening mechanisms in the AuCuNiPdPt alloy were assessed as follows: The contribution of solid solution hardening to the total strength has been determined according to the model of C. Varvenne et al. [49]. The effect of the grain size on the total strength has been evaluated upon recrystallised samples that have been additionally heat treated for different times in order to obtain different grain sizes. As these samples were not subjected to deformation, the effect of work hardening is neglected. Other measures such as precipitation or dispersion strengthening are not relevant 
for the present alloy.

Modelling of solid solution strengthening. The most commonly used model to describe solid solution strengthening in fcc HEAs is the model derived by C. Varvenne et al. [49]. They propose that the solute strengthening in a HEA can be described by an effective average matrix ("solvent") with all atoms being embedded "solute" atoms. Here, the average matrix represents the mean properties of the HEA, while the embedded solutes account for the local chemical fluctuations [49-51].

The full parametrisation of the model includes chemical and elastic interactions between the dislocation and the HEA matrix [49, 51]. Commonly, a reduced form including only elastic contributions is used. This reduced form has been applied to different noble metal HEAs [52, 53]. Eqs. 3-5 give the critical shear stress for dislocation glide $\tau_{\mathrm{y}}$ as function of temperature $T$ and strain rate $\dot{\varepsilon}$ :

$$
\begin{aligned}
\tau_{\mathrm{y}}(T, \dot{\varepsilon}) & =\tau_{\mathrm{y} 0}\left[1-\left(\frac{k_{\mathrm{B}} T}{\Delta E_{\mathrm{b}}} \ln \frac{\dot{\varepsilon_{0}}}{\dot{\varepsilon}}\right)^{\frac{2}{3}}\right], \text { with } \\
\tau_{\mathrm{y} 0} & =0.01785 \alpha^{-\frac{1}{3}} \bar{G}\left(\frac{1+\bar{\nu}}{1-\bar{\nu}}\right)^{\frac{4}{3}}\left[\frac{\sum_{n} c_{n} \Delta V_{n}^{2}}{b^{6}}\right]^{\frac{2}{3}}, \text { and } \\
\Delta E_{\mathrm{b}} & =1.56318 \alpha^{\frac{1}{3}} \bar{G} b^{3}\left(\frac{1+\bar{\nu}}{1-\bar{\nu}}\right)^{\frac{2}{3}}\left[\frac{\sum_{n} c_{n} \Delta V_{n}^{2}}{b^{6}}\right]^{\frac{1}{3}},
\end{aligned}
$$

where $\bar{G}$ is the shear modulus of the HEA, $\bar{\nu}$ is the Poisson's ratio of the alloy, $c_{n}$ is the concentration of element $n, \Delta V_{n}$ is the so-called misfit volume, $b$ is the length of the Burgers vector, and $k_{\mathrm{B}}$ is the Boltzmann constant. In-line with Varvenne \& Curtin [52], we chose the following parameters: $\alpha=0.123$, $\dot{\varepsilon}=10^{-4} \mathrm{~s}^{-1}$, and $\dot{\varepsilon}_{0}=10^{4} \mathrm{~s}^{-1}$ [49]. Using a Taylor factor of $3.06, \tau_{\mathrm{y}}$ can be converted to the tensile yield strength $\sigma_{\mathrm{y}}^{\text {theo. }}$.

As many of the input properties of the model are not known for the AuCuNiPdPt alloy we follow the approach taken in Ref. [52] and use a ruleof-mixture based on established literature data, with $\bar{G}=\sum_{n} c_{n} G_{n}$ and $\bar{\nu}=\bar{E} /(2 \bar{G}-1)$, where the Young's modulus $\bar{E}$ of the HEA is equal to $\sum_{n} c_{n} E_{n}$. Following Vegard's law [54], the mean atomic volume of the alloy is $\bar{V}=\sum_{n} c_{n} V_{n}$, which can be used to calculate the misfit volume $\Delta V_{n}=$ $V_{n}-\bar{V}$. Note, that for fcc $V_{n}=a_{0}^{3} / 4$, where $a_{0}$ is the lattice constant. Further, $b=\sqrt{2} / 2 \sqrt[3]{4 \bar{V}}$ is the shortest interatomic distance in the fcc lattice. 
While Yin \& Curtin [53] have shown that this rule-of-mixture might not be sufficient to accurately determine the yield strength, it should be valid to judge the magnitude of solid solution strengthening in the AuCuNiPdPt alloy.

Using the methodology outlined above and the literature data given in table 4, we calculate a theoretical tensile yield strength of $592 \mathrm{MPa}$ at $300 \mathrm{~K}$, which is in-line with other noble metal HEAs [52, 53]. From these calculations we can conclude that solid solution strengthening provides a substantial contribution to the very high yield strength measured for the $\mathrm{AuCuNiPdPt}$ HEA.

Assessment of Hall-Petch type strengthening. For the evaluation of the HallPetch hardening, AuCuNiPdPt samples were recrystallised for different times. This annealing procedure causes recrystallisation as well as grain growth, which is dependent on the annealing time. The dependence of the yield strength, as determined upon three compression tests on the inverse square root of the grain size is shown in Fig. 12. A linear fit of the data yields a Hall-Petch coefficient of $0.675 \mathrm{MPa} / \sqrt{\mathrm{m}}$. This value is somewhat higher compared to what has been observed for the CoCrFeMnNi high-entropy alloy, i.e. $0.5 \mathrm{MPa} / \sqrt{\mathrm{m}}[10]$, while it is comparable to the value of the medium-entropy alloy CoCrNi, i.e. $0.6 \mathrm{MPa} / \sqrt{\mathrm{m}}[55]$. Extrapolating the present experimentally observed values (Fig. 12) to an infinite grain size gives a strength level of $750 \mathrm{MPa}$, i.e. this value is representative for the strength without the effect of the grain size.

The total yield strength of $\mathrm{AuCuNiPdPt}$ is assessed upon a superposition of the individual strengthening mechanisms, i.e.

$$
\tau=\tau_{0}+\Delta \tau_{\mathrm{c}}
$$

Here $\tau$ represents the yield strength of the sample, $\tau_{0}$ the friction stress and $\Delta \tau_{\mathrm{c}}$ is the contribution to the yield strength due to the before mentioned strengthening mechanisms. However, there is no general accepted formula for the calculation of $\Delta \tau_{\mathrm{c}}$ and an empirical equation has widely been used [56]:

$$
\Delta \tau_{\mathrm{c}}=\sqrt[k]{\sum_{i} \Delta \tau_{\mathrm{c}, \mathrm{i}}^{k}}
$$

The exponent $k$ is typically in between 1 and 2 , while $k=1$ is justified when the individual mechanisms have different strengths, while $k=2$ is seen 
for the case when the mechanisms are comparable in effect. In the present case the obstacles for dislocation slip are either a few $\mathrm{nm}$ for solid solution strengthening or several $\mu m$ for grain boundary strengthening. Hence $k=1$ would be more likely.

Table 5 shows the corresponding strength values for the weakest and strongest sample under investigation. While the contribution of solid solution hardening remains at the same level, the Hall-Petch type hardening is different. As can be seen, the yield strength is altered in the same magnitude and the evaluated friction stress is about the same for both cases. This is another indication that $k=1$ is justified, especially as $\tau_{0}$ would alter by approx. $30 \%$ for both cases when $k=2$ would be assumed. The apparent friction stress of $\tau_{0} \simeq 160 \mathrm{MPa}$ is very high. However, current modelling of the solid solution strengthening of High Entropy Alloys is still under development.

The high strength of this HEA would not have been expected from the mechanical properties of the five base metals, which are rather soft. In addition, the well established fcc single phase CoCrFeMnNi HEA to which the $\mathrm{AuCuNiPdPt}$ alloy can be compared to, shows a lower yield strength, i.e. $200-400 \mathrm{MPa}[10,11,18,22,24]$. Besides the higher yield point the AuCuNiPdPt HEA shows a much higher yield ratio of 0.66 in the recrystallised state and 0.9 in the cold worked state. For comparison: The values being reported for the CoCrFeMnNi alloy in the recrystallised state range from 0.4 to $0.5[10,11,18,22,24]$. The origin of the high strength of the $\mathrm{AuCu}-$ NiPdPt HEA, its high friction stress and its high yield ratio has not yet been determined.

\section{Conclusions}

The precious metal based High-Entropy Alloy AuCuNiPdPt crystallises in the face-centred cubic Cu-type structure. The alloy is single phase after homogenisation at an appropriate temperature and rapid water-quenching with no chemical ordering or inhomogeneities visible from XRD, EDX or APT measurements. However, a decomposition occurs in consequence of annealing at intermediate temperatures, proving the metastability of this HEA.

During cold work the texture of the recrystallised AuCuNiPdPt HEA develops towards a $\langle 001\rangle /\langle 111\rangle$ fibre texture with a dominating $\langle 111\rangle$ fibre which is a typical behaviour for conventional as well as multi-principal component fcc alloys deformed by uniaxial elongation. Deformation twinning 
predominantly occurs in $\langle 111\rangle$-oriented grains. Localised dislocation slip, i.e. slip band formation, was seen after the initial deformation state in any grain independent of its orientation. This is an indirect evidence for extended stacking faults typically appearing in materials with a low stacking fault energy.

In the recrystallised state, this alloy shows a yield strength of approx. $820 \pm 15 \mathrm{MPa}$ as determined from compression and tension tests. The analysis of the strengthening mechanisms reveals a contribution to the yield strength by solid solution strengthening of $591 \mathrm{MPa}$, while the Hall-Petch type strengthening mechanism provides values ranging from 40 to $110 \mathrm{MPa}$ depending on the grain size. The calculated friction stress is apparantly as high as $160 \mathrm{MPa}$. Furthermore, a yield ratio of 0.66 at room temperature and sufficient ductility to allow cold work by means of rotary swaging up to a logarithmic deformation degree of $\varphi=2.4$ are observed. Starting from the recrystallised state, cold work causes a significant increase of the yield strength to approximately $1.1 \mathrm{GPa}$ above $\varphi=0.6$. The hardness shows the same qualitative behaviour, including saturation at larger degrees of deformation. This is in good accordance with the behaviour of mean lattice strain determined by modified Williamson-Hall analysis showing a similar saturation. The steep increase of strength is associated with deformation twinning as well as dislocation mediated work hardening which is enhanced by the introduction of additional twin grain boundaries. Further, the formation of twins contributes to the refinement of the microstructure and, thus, to the strength of the work hardened alloy. The saturation of work hardening at later deformation stages follows the common theory of plastic deformation.

The AuCuNiPdPt HEA can be used as benchmark for fcc, single-phase HEAs when investigating solid solution strengthening, since it allows wide changes of the composition without loosing the single-phase nature.

\section{Acknowledgement}

This work was supported by the Deutsche Forschungsgemeinschaft (DFG) within the priority programme Compositionally Complex Alloys - High-Entropy Alloys (CCA-HEA) (SPP 2006, grant nos. FR 1714/7-1 (FT, JF), KA 4631/1-1 (AK) and STU 611/2-1 (DU, KA)). This financial support is greatfully acknowledged. This work was partly carried out with the support of the Karlsruhe Nano Micro Facility (KNMF, www.knmf.kit.edu), a Helmholtz Research Infrastructure at Karlsruhe Institute of Technology (KIT, www.kit.edu). 
Furthermore, we would like to express our gratitude to C. Bollnow, S. Donath, B. Gebel, A. Pöhl, J. Scheiter and D. Seifert for experimental support.

\section{References}

[1] D. Raabe, Texture and microstructure evolution during cold rolling of a strip cast and of a hot rolled austenitic stainless steel, Acta Materialia 45 (1997) 1137-1151. doi:10.1016/S1359-6454(96)00222-4.

[2] F. Yan, N. Tao, F. Archie, I. Gutierrez-Urrutia, D. Raabe, K. Lu, Deformation mechanisms in an austenitic single-phase duplex microstructured steel with nanotwinned grains, Acta Materialia 81 (2014) 487 500. doi:10.1016/j.actamat.2014.08.054.

[3] B. De Cooman, Y. Estrin, S. K. Kim, Twinning-induced plasticity (TWIP) steels, Acta Materialia 142 (2018) 283 - 362. doi:10.1016/j.actamat.2017.06.046.

[4] H. Biermann, J. Solarek, A. Weidner, SEM Investigation of High-Alloyed Austenitic Stainless Cast Steels With Varying Austenite Stability at Room Temperature and $100^{\circ} \mathrm{C}$, steel research international 83 (2012) 512-520. doi:10.1002/srin.201100293.

[5] D. Geissler, J. Freudenberger, A. Kauffmann, M. Krautz, H. Klauß, A. Voss, J. Eickemeyer, L. Schultz, Appearance of dislocationmediated and twinning-induced plasticity in an engineeringgrade FeMnNiCr alloy, Acta Materialia 59 (2011) 7711-7723. doi:10.1016/j.actamat.2011.08.040.

[6] J.-W. Yeh, S.-K. Chen, S.-J. Lin, J.-Y. Gan, T.-S. Chin, T.-T. Shun, C.-H. Tsau, S.-Y. Chang, Nanostructured High-Entropy Alloys with Multiple Principal Elements: Novel Alloy Design Concepts and Outcomes, Advanced Engineering Materials 6 (5) (2004) 299-303. doi:10.1002/adem.200300567.

[7] B. Cantor, I. Chang, P. Knight, A. Vincent, Microstructural development in equiatomic multicomponent alloys, Materials Science and Engineering: A 375-377 (C) (2004) 213 - 218. doi:10.1016/j.msea.2003.10.257. 
[8] Deutsche Forschungs Gemeinschaft, Priority Programme Compositionally Complex Alloys - High Entropy Alloys (CCA-HEA) (SPP 2006), information für die Wissenschaft Nr. 65 (2016).

URL https://www.dfg.de/foerderung/info_wissenschaft/2016/info_wissenschaft_16_

[9] D. Miracle, O. Senkov, A critical review of high entropy alloys and related concepts, Acta Materialia 122 (2017) 448 - 511. doi:10.1016/j.actamat.2016.08.081.

[10] F. Otto, A. Dlouhý, C. Somsen, H. Bei, G. Eggeler, E. George, The influences of temperature and microstructure on the tensile properties of a CoCrFeMnNi high-entropy alloy, Acta Materialia 61 (2013) 5743 5755. doi:10.1016/j.actamat.2013.06.018.

[11] B. Gludovatz, A. Hohenwarter, D. Catoor, E. Chang, E. George, R. Ritchie, A fracture-resistant high-entropy alloy for cryogenic applications, Science 345 (2014) 1153-1158. doi:10.1126/science.1254581.

[12] J. Freudenberger, D. Rafaja, D. Geissler, L. Giebeler, C. Ullrich, A. Kauffmann, M. Heilmaier, K. Nielsch, Face Centred Cubic MultiComponent Equiatomic Solid Solutions in the Au-Cu-Ni-Pd-Pt System, Metals 7 (4) (2017) 135. doi:10.3390/met7040135.

[13] C. Zhang, F. Zhang, H. Diao, M. C. Gao, Z. Tang, J. D. Poplawsky, P. K. Liaw, Understanding phase stability of Al-Co-CrFe-Ni high entropy alloys, Materials \& Design 109 (2016) 425 - 433. doi:10.1016/j.matdes.2016.07.073.

[14] H. Song, F. Tian, D. Wang, Thermodynamic properties of refractory high entropy alloys, Journal of Alloys and Compounds 682 (2016) 773 777. doi:10.1016/j.jallcom.2016.04.320.

[15] O. Senkov, G. Wilks, D. Miracle, C. Chuang, P. Liaw, Refractory high-entropy alloys, Intermetallics 18 (9) (2010) 1758 - 1765. doi:10.1016/j.intermet.2010.05.014.

[16] M. Feuerbacher, M. Heidelmann, C. Thomas, Hexagonal Highentropy Alloys, Materials Research Letters 3 (1) (2015) 1-6. doi:10.1080/21663831.2014.951493. 
[17] The Landolt Börnstein database (2019). URL http://materials.springer.com

[18] B. Gludovatz, E. George, R. Ritchie, Processing, Microstructure and Mechanical Properties of the CrMnFeCoNi High-Entropy Alloy, JOM 67 (10) (2015) 2262-2270. doi:10.1007/s11837-015-1589-z.

[19] S. Hong, J. Moon, S. Hong, H. Kim, Thermally activated deformation and their rate controlling mechanism in $\mathrm{CoCrFeMnNi}$ high entropy alloy, Materials Science and Engineering A 682 (2017) 569 - 576. doi:10.1016/j.msea.2016.11.078.

[20] B. Schuh, F. Mendez-Martin, B. Völker, E. George, H. Clemens, R. Pippan, A. Hohenwarter, Mechanical properties, microstructure and thermal stability of a nanocrystalline $\mathrm{CoCrFeMnNi}$ high-entropy alloy after severe plastic deformation, Acta Materialia 96 (2015) 258 - 268. doi:10.1016/j.actamat.2015.06.025.

[21] F. Otto, A. Dlouhý, K. Pradeep, M. Kuběnová, D. Raabe, G. Eggeler, E. George, Decomposition of the single-phase high-entropy alloy CrM$\mathrm{nFeCoNi}$ after prolonged anneals at intermediate temperatures, Acta Materialia 112 (2016) 40 - 52. doi:j.actamat.2016.04.005.

[22] G. Laplanche, A. Kostka, O. Horst, G. Eggeler, E. George, Microstructure evolution and critical stress for twinning in the CrMnFeCoNi high-entropy alloy, Acta Materialia 118 (2016) 152 - 163. doi:10.1016/j.actamat.2016.07.038.

[23] R. Raghaven, C. Kirchlechner, B. Jaya, M. Feuerbacher, G. Dehm, Mechanical size effects in a single crystalline equiatomic FeCrCoMnNi high entropy alloy, Scripta Materialia 129 (2017) 52-55. doi:10.1016/j.scriptamat.2016.10.026.

[24] A. Tirunilai, J. Sas, K.-P. Weiss, H. Chen, D. Szabó, S. Schlabach, S. Haas, D. Geissler, J. Freudenberger, M. Heilmaier, A. Kauffmann, Peculiarities of deformation of $\mathrm{CoCrFeMnNi}$ at cryogenic temperatures, Journal of Materials Research 33 (2018) 3287 - 3300. doi:10.1557/jmr.2018.252. 
[25] A. Gali, E. George, Tensile properties of high- and medium-entropy alloys, Intermetallics 39 (2013) 74 - 78 . doi:10.1016/j.intermet.2013.03.018.

[26] W. Liu, Y. Wu, J. He, T. Nieh, Z. Lu, Grain growth and the Hall-Petch relationship in a high-entropy FeCrNiCoMn alloy, Scripta Materialia 68 (2013) 526 - 529. doi:10.1016/j.scriptamat.2012.12.002.

[27] A. Kilmametov, R. Kulagin, A. Mazilkin, S. Seils, T. Boll, M. Heilmaier, H. Hahn, High-pressure torsion driven mechanical alloying of CoCrFeMnNi high entropy alloy, Scripta Materialia 158 (2019) 29 - 33. doi:10.1016/j.scriptamat.2018.08.031.

[28] D. Larson, T. Prosa, R. Ulfig, B. Geiser, T. Kelly, Local Electrode Atom Probe Tomography, Springer, 2013.

[29] Z. Li, S. Zhao, R. Ritchie, M. Meyers, Mechanical Properties of high-entropy alloys with emphasis on face-centered cubic alloys, Progress in Materials Science 102 (2019) 296 - 345. doi:10.1016/j.pmatsci.2018.12.003.

[30] E. P. George, D. Raabe, R. O. Ritchie, High-entropy alloys, Nature Reviews Materialsdoi:10.1038/s41578-019-0121-4.

[31] S. Haas, M. Mosbacher, O. Senkov, M. Feuerbacher, J. Freudenberger, S. Gezgin, U. Völkl, R. Glatzel, Entropy Determination of Single-Phase High Entropy Alloys with Different Crystal Structures over a Wide Temperature Range, Entropy 20 (9). doi:10.3390/e20090654.

[32] M. Moody, L. Stephenson, A. Ceguerra, S. Ringer, Quantitative binomial distribution analyses of nanoscale like-solute atom clustering and segregation in atom probe tomography data, Microscopy Research and Technique 71 (2008) 542-550. doi:10.1002/jemt.20582.

[33] A. Kauffmann, J. Freudenberger, D. Geissler, S. Yin, W. Schillinger, V. S. Sarma, H. Bahmanpour, R. Scattergood, M. Khoshkhoo, H. Wendrock, C. Koch, J. Eckert, L. Schultz, Severe deformation twinning in pure copper by cryogenic wire drawing, Acta Materialia 59 (2011) 78167823. doi:10.1016/j.actamat.2011.08.042. 
[34] E. El-Danaf, S. Kalidindi, R. Doherty, Influence of grain size and stacking-fault energy on deformation twinning in fcc metals, Metallurgical and Materials Transactions A 30 (1999) 1223-1233. doi:10.1007/s11661-999-0272-9.

[35] Z. Jin, T. Bieler, An in-situ observation of mechanical twin nucleation and propagation in TiAl, Philosophical Magazine A 71 (1995) 925-947. doi:10.1080/01418619508236229.

[36] S. Krishnamurthy, R. E. Reed-Hill, Concerning the role of mechanical twinning on the stress-strain behavior of Cu-4.9 At. pct Sn alloy, Metallurgical Transactions A 11 (1980) 565-572. doi:10.1007/BF02670693.

[37] D. Geissler, J. Freudenberger, A. Kauffmann, S. Martin, D. Rafaja, Assessment of the thermodynamic dimension of the stacking fault energy, Philosophical Magazine 94 (2014) 2967-2979. doi:10.1080/14786435.2014.944606.

[38] D. Borisova, V. Klemm, S. Martin, S. Wolf, D. Rafaja, Microstructure defects contributing to the energy absorption in crmnni trip steels, Advanced Engineering Materials 15 (2013) 571-582. doi:10.1002/adem.201200327.

[39] A. Schwartz, M. Kumar, B. A. . D. Field (Eds.), Electron Backscatter Diffraction in Materials Science, 2nd Edition, Springer, 2009. doi:10.1007/978-0-387-88136-2.

[40] J. Venables, Deformation twinning in face-centred cubic metals, Philosophical Magazine 6 (1961) 379-396. doi:10.1080/14786436108235892.

[41] G. Williamson, W. Hall, X-ray line broadening from filed aluminium and wolfram, Acta Metallurgica 1 (1953) 22-31. doi:10.1016/00016160(53)90006-6.

[42] B. Warren, X-ray Diffraction, Dover Inc., 1990.

[43] S. Martin, C. Ullrich, D. Šimek, U. Martin, D. Rafaja, Stacking fault model of $\varepsilon$-martensite and its DIFFaX implementation, Journal of Applied Crystallography 44 (2011) 779-787. doi:10.1107/S0021889811019558. 
[44] T. Ungár, I. Dragomir, A. Revesz, A. Borbély, The contrast factors of dislocations in cubic crystals: the dislocation model of strain anisotropy in practice, Journal of Applied Crystallography 32 (1999) 992-1002. doi:10.1107/S0021889899009334.

[45] T. Ungár, Microstructural parameters from X-ray diffraction peak broadening, Scripta Materialia 51 (2004) 777-781. doi:10.1016/j.scriptamat.2004.05.007.

[46] D. Šimek, D. Rafaja, M. Motylenko, V. Klemm, G. Schreiber, A. Brethfeld, G. Lehmann, Xrd analysis of lokal strain fields in pearlitic steels towards the fast examination of microstructure after hot rolling, Steel Research International 79 (2008) 800-805. doi:10.1002/srin.200806201.

[47] D. Šimek, D. Rafaja, M. Motylenko, V. Klemm, C. Ullrich, A. Oswald, R. Schmidtchen, G. Lehmann, The exploitation of x-ray diffraction in characterization of strength of hot-rolled and cold-drawn ferriticpearlitic steel, Materials Structure 18 (2011) 178-183.

[48] T. Ungár, A. Borbély, The effect of dislocation contrast on x-ray line broadening: A new approach to line profile analysis, Applied Physics Letters 69 (1996) 3173-3175.

[49] C. Varvenne, A. Luque, W. A. Curtin, Theory of strengthening in fcc high entropy alloys, Acta Materialia 118 (2016) 164-176. doi:10.1016/j.actamat.2016.07.040.

[50] C. Varvenne, A. Luque, W. G. Nöhring, W. A. Curtin, Average-atom interatomic potential for random alloys, Physical Review B 93 (10). doi:10.1103/physrevb.93.104201.

[51] C. R. LaRosa, M. Shih, C. Varvenne, M. Ghazisaeidi, Solid solution strengthening theories of high-entropy alloys, Materials Characterization 151 (2019) 310 - 317. doi:10.1016/j.matchar.2019.02.034.

[52] C. Varvenne, W. A. Curtin, Predicting yield strengths of noble metal high entropy alloys, Scripta Materialia 142 (2018) 92-95. doi:10.1016/j.scriptamat.2017.08.030. 
[53] B. Yin, W. A. Curtin, First-principles-based prediction of yield strength in the $\mathrm{RhIrPdPtNiCu}$ high-entropy alloy, npj Computational Materials 5 (1). doi:10.1038/s41524-019-0151-x.

[54] L. Vegard, Die konstitution der mischkristalle und die raumfüllung der atome, Zeitschrift für Physik 5 (1) (1921) 17-26. doi:10.1007/BF01349680.pdf.

[55] M. Schneider, E. George, T. Manescau, T. Zalezak, J. Hunfeld, A. Dlouhy, G. Eggeler, G. Laplanche, Analysis of strengthening due to grain boundaries and annealing twin boundaries in the CrCoNi mediumentropy alloy, International Journal of PlasticityIn press.

[56] U. Kocks, A. Argon, M. Ashby, Thermodynamics and kinetics of slip, Progress in Materials Science 19 (1975) 1.

[57] W. Martienssen, H. Warlimont (Eds.), Springer Handbook of Materials Data, Springer, Berlin, Heidelberg, 2018, Ch. Metals, pp. 147-438. doi:10.1007/978-3-319-69743-7. 
Table 1: Compositions of the sample as obtained locally from EDX analysis. The point analysis was made on both phases as indicated by arrows evaluating 10 individual measurements each. The corresponding SEM image and the EDX maps are shown in Fig. 3. Values are provided in at.\%.

\begin{tabular}{lccccc}
\hline \hline element & $\mathrm{Au}$ & $\mathrm{Cu}$ & $\mathrm{Ni}$ & $\mathrm{Pd}$ & $\mathrm{Pt}$ \\
\hline bright phase (1) & $29.4 \pm 0.6$ & $24.2 \pm 0.7$ & $10.2 \pm 0.6$ & $24.0 \pm 0.4$ & $12.1 \pm 0.3$ \\
dark phase (2) & $7.7 \pm 0.6$ & $13.6 \pm 0.2$ & $31.3 \pm 0.5$ & $12.1 \pm 0.4$ & $35.3 \pm 0.3$ \\
\hline \hline
\end{tabular}

Table 2: Composition of the sample as obtained locally from EDX point analysis by evaluating 10 individual measurements which cover the whole scanning area. The corresponding SEM image is shown in Fig. 1(b). Values are provided in at.\%

\begin{tabular}{cccccc}
\hline \hline element & $\mathrm{Au}$ & $\mathrm{Cu}$ & $\mathrm{Ni}$ & $\mathrm{Pd}$ & $\mathrm{Pt}$ \\
\hline & $20.2 \pm 0.9$ & $18.7 \pm 0.3$ & $19.8 \pm 0.5$ & $18.8 \pm 0.2$ & $22.5 \pm 0.9$ \\
\hline \hline
\end{tabular}


Table 3: Compositions of the sample as obtained from APT analysis covering the entire tip after peak deconvolution as seen from Fig. 4(a). Values are provided in at.\%. The Pearson coefficient $\mu$ quantifies the deviation between binomial and experimental distribution of the frequency distribution shown in Fig. 4(c).

\begin{tabular}{cccccc}
\hline \hline element & $\mathrm{Au}$ & $\mathrm{Cu}$ & $\mathrm{Ni}$ & $\mathrm{Pd}$ & $\mathrm{Pt}$ \\
\hline & $18.8 \pm 0.1$ & $19.7 \pm 0.1$ & $20.9 \pm 0.1$ & $20.1 \pm 0.1$ & $20.3 \pm 0.1$ \\
$\mu$ & 0.05 & 0.04 & 0.04 & 0.06 & 0.07 \\
\hline \hline
\end{tabular}

Table 4: Literature data of the properties for the pure elements contained in the HEA taken from the "Springer Handbook of Materials Data" [57]. $a_{0}$ is the fcc lattice constant, $E$ the Young's modulus, and $G$ the shear modulus. The HEA misfit volume $\Delta V$ is calculated as outlined in Section 3.3.2.

\begin{tabular}{lcccccc}
\hline \hline \multicolumn{2}{l}{ element } & $\mathrm{Au}$ & $\mathrm{Cu}$ & $\mathrm{Ni}$ & $\mathrm{Pd}$ & $\mathrm{Pt}$ \\
\hline$a_{0}$ & $\AA$ & 4.078 & 3.615 & 3.524 & 3.890 & 3.923 \\
$\Delta V$ & $\AA^{3}$ & 3.054 & -2.096 & -2.963 & 0.812 & 1.192 \\
$E$ & $\mathrm{GPa}$ & 78 & 128.8 & 220 & 121 & 170 \\
$G$ & $\mathrm{GPa}$ & 26 & 46.8 & 78.5 & 43.5 & 60.9 \\
\hline \hline
\end{tabular}

Table 5: Strength values of the individual strengthening mechanisms $\Delta \tau_{\mathrm{c}, \mathrm{i}}$, experimentally determined yield strenght $\tau$ as well as calculated friction stress $(k=1)$ of two conditions with different grain sizes. $\tau_{\mathrm{c}, \mathrm{ss}}$ is representative for the solid solution strenghtening, while $\tau_{\mathrm{c}, \mathrm{HP}}$ symbolises the Hall-Petch type strengthening mechanism.

\begin{tabular}{rcc}
\hline \hline condition & 1 & 2 \\
\hline grain size in $\mu m$ & 35.2 & 252.8 \\
$\tau$ in $\mathrm{MPa}$ & 865 & 790 \\
$\tau_{0}$ in $\mathrm{MPa}$ & 164 & 159 \\
$\tau_{\mathrm{c}, \mathrm{ss}}$ in $\mathrm{MPa}$ & 591 & 591 \\
$\tau_{\mathrm{c}, \mathrm{HP}}$ in $\mathrm{MPa}$ & 110 & 40 \\
\hline \hline
\end{tabular}




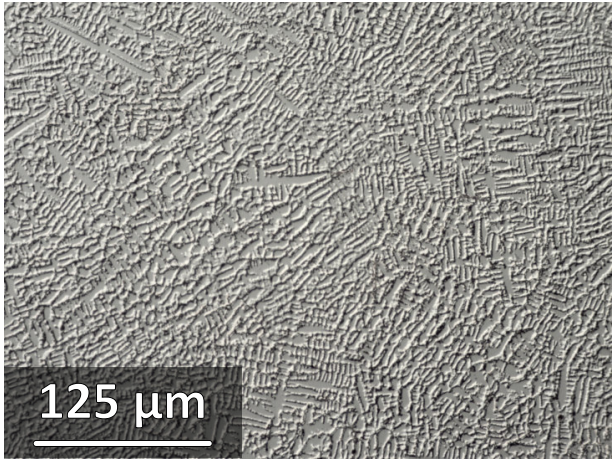

(a)

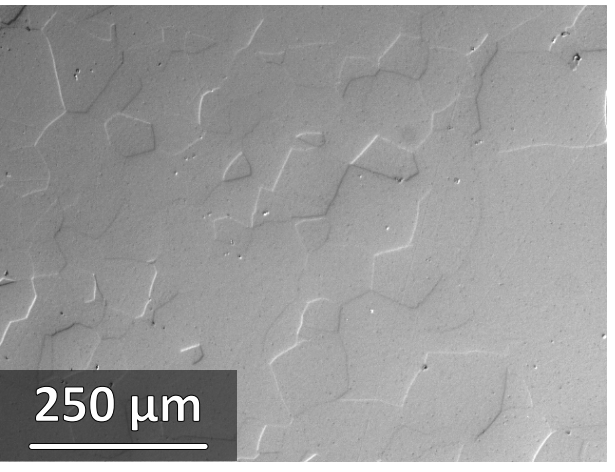

(b)

Figure 1: Microstructure of AuCuNiPdPt in the (a) as-cast state as well as (b) after the homogenisation at $1100{ }^{\circ} \mathrm{C}$ for $20 \mathrm{~h}$. Both images are taken by means of light optical microscopy. 

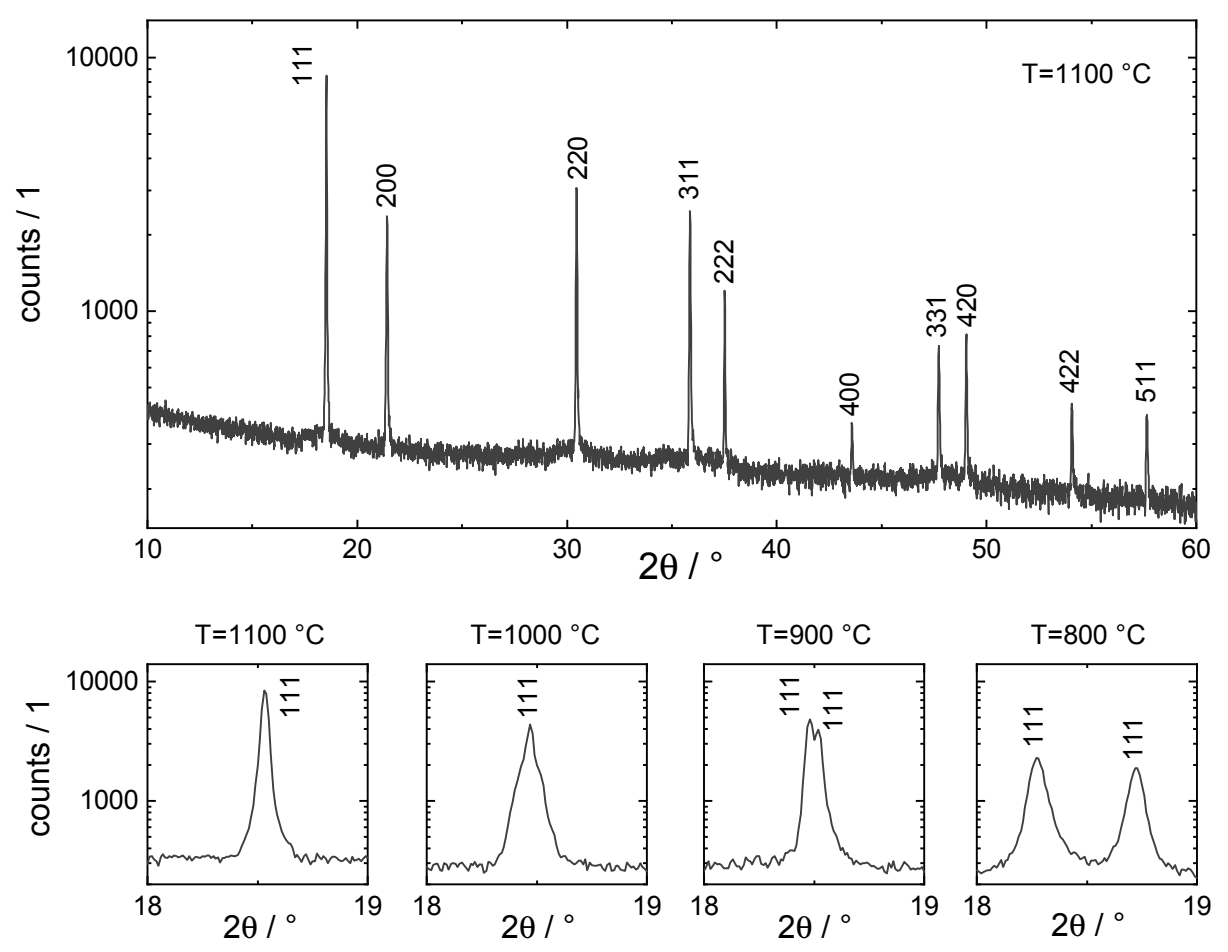

Figure 2: X-ray diffraction pattern of AuCuNiPdPt observed after homogenisation at $1100{ }^{\circ} \mathrm{C}$ for $20 \mathrm{~h}$ (upper part). Below the entire pattern, sections of the (111) reflection are shown. These correspond to samples heat treated for $20 \mathrm{~h}$ at the given temperatures ranging from $800{ }^{\circ} \mathrm{C}$ to $1100{ }^{\circ} \mathrm{C}$. 


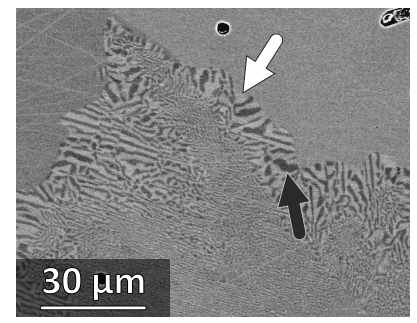

(a)

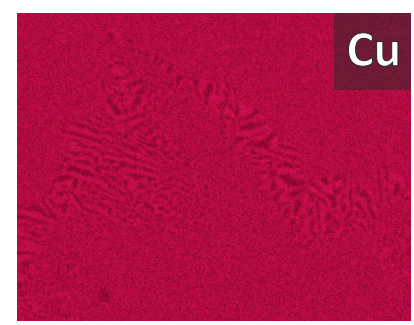

(d)

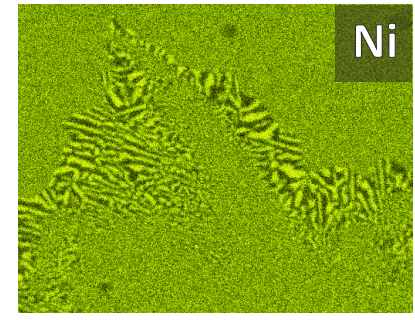

(b)

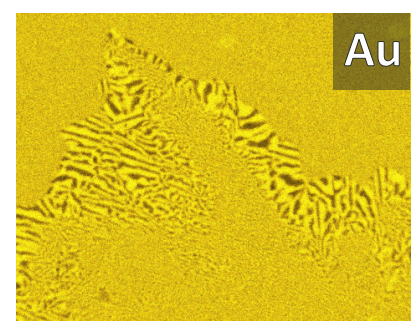

(e)

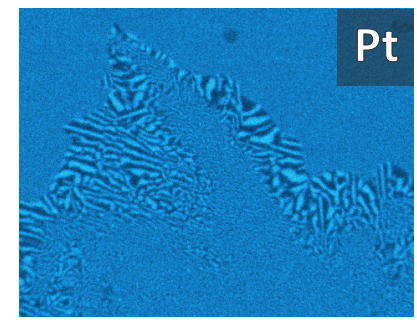

(c)

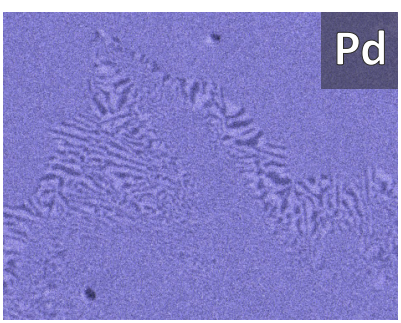

(f)

Figure 3: Microstructure (a) as obtained from SEM utilising BSE imaging of AuCuNiPdPt annealed at $800^{\circ} \mathrm{C}$ for $20 \mathrm{~h}$ as well as elemental mappings (b) to (f) obtained from EDX. The white arrow points to the $\mathrm{Au}-\mathrm{Cu}$ - and $\mathrm{Pd}$-rich phase. The black arrow points to the Ni- and Pt-rich phase. 


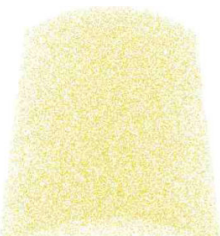

$\mathrm{Au}$

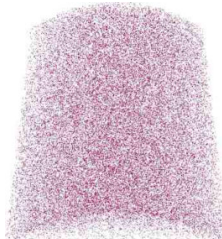

$\mathrm{Cu}$
$\mathrm{Ni}$

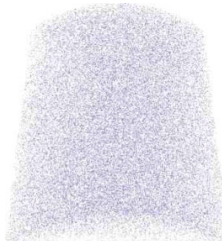

$\mathrm{Pd}$

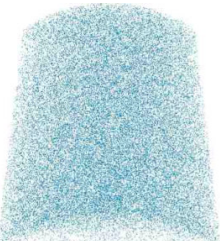

$\mathrm{Pt}$

$50 \mathrm{~nm}$

(a)

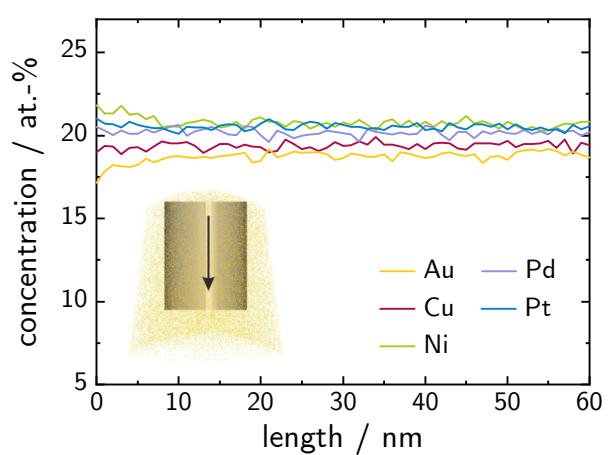

(b)

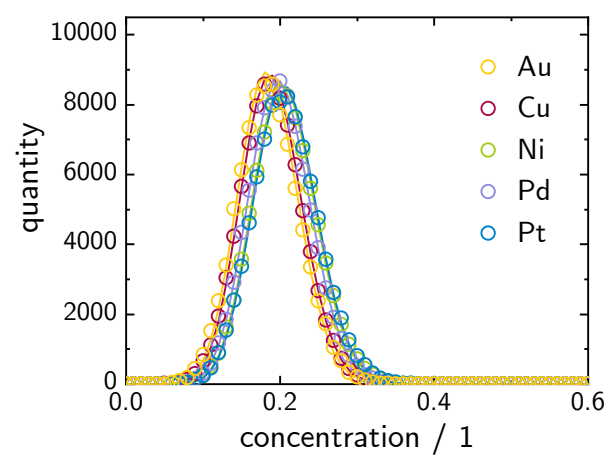

(c)

Figure 4: APT analysis of AuCuNiPdPt. (a) element distributions, (b) 1-D element distribution along a cylinder of $50 \mathrm{~nm}$ in diameter (uncorrected rel. counts) and (c) frequency distribution of the concentration. The concentration profile was taken with a step size of $1 \mathrm{~nm}$. 


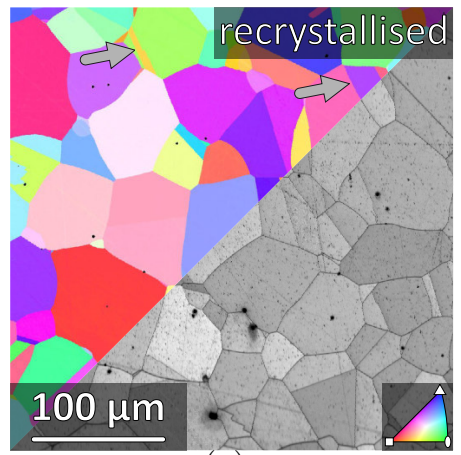

(a)

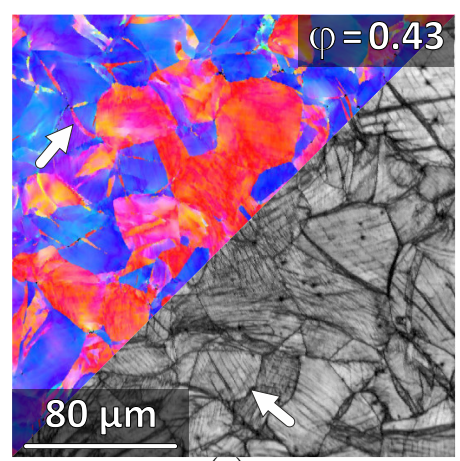

(c)

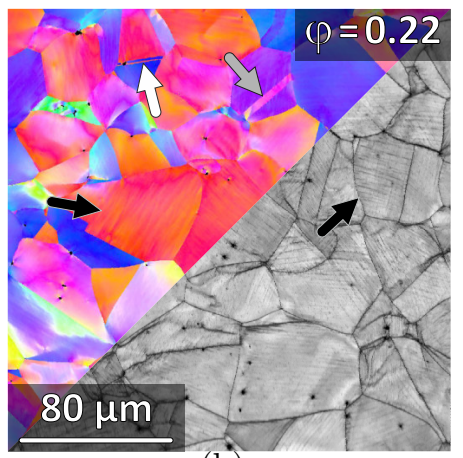

(b)

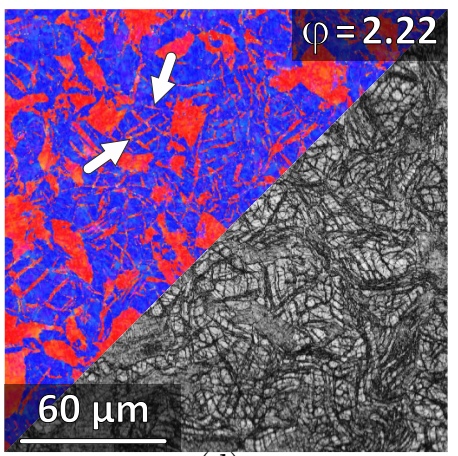

(d)

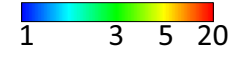

(e)

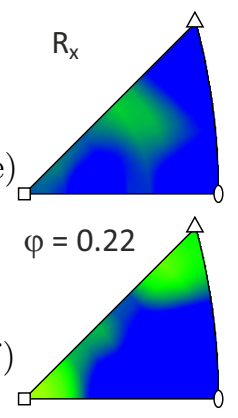

(g)

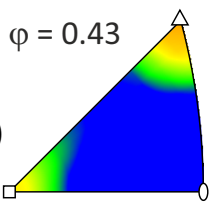

(h)

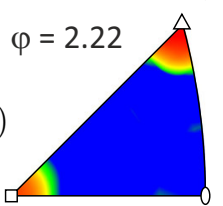

Figure 5: Orientation imaging microscopy: orientation mapping with colour code according to the inverse pole figure of the wire axis $(\langle 111\rangle,\langle 011\rangle$ and $\langle 001\rangle)$ and image quality as grey scale images on the cross section of AuCuNiPdPt in (a) the recrystallised state and (b) various stages of cold work are shown. The corresponding IPFs are depicted in (e) - (h). The scaling is given in multiples of the uniform distribution (m.u.d.).

Grey arrows indicate recrystallisation twins and white arrows indicate deformation twins, respectively. Black arrows point to grains with slip bands. 


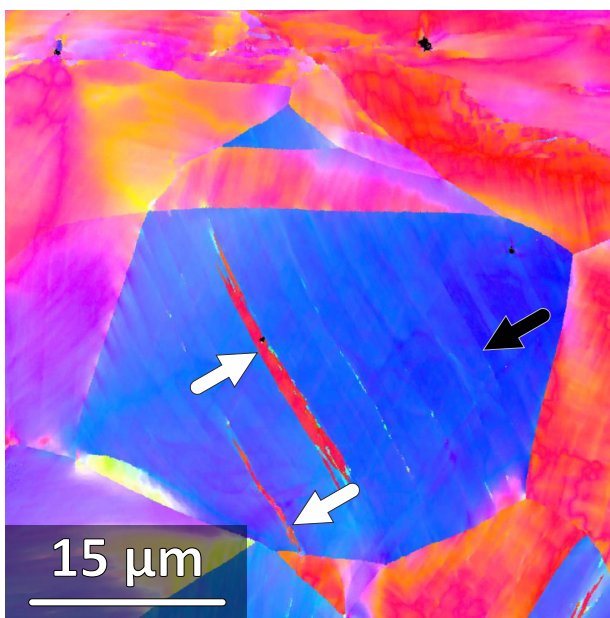

(a)

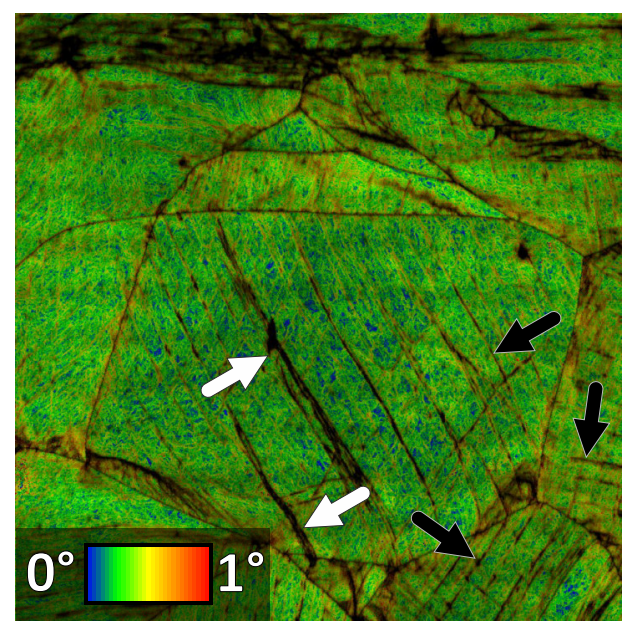

(b)

Figure 6: Orientation imaging microscopy: high-resolution image of the cross-section area of $\mathrm{AuCuNiPdPt}$ after cold work to $\varphi=0.43$ pointed at with a white arrow in the image quality map of Fig. 5(c) depicted as (a) orientation mapping and image quality as well as (b) the kernal average misorientation map. The white arrows indicate indexed deformation twins. The black arrows point at localised deformation bands. 


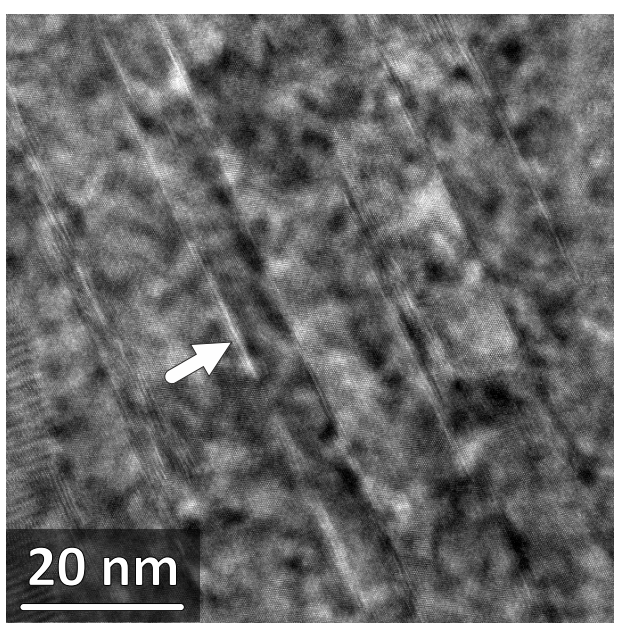

(a)

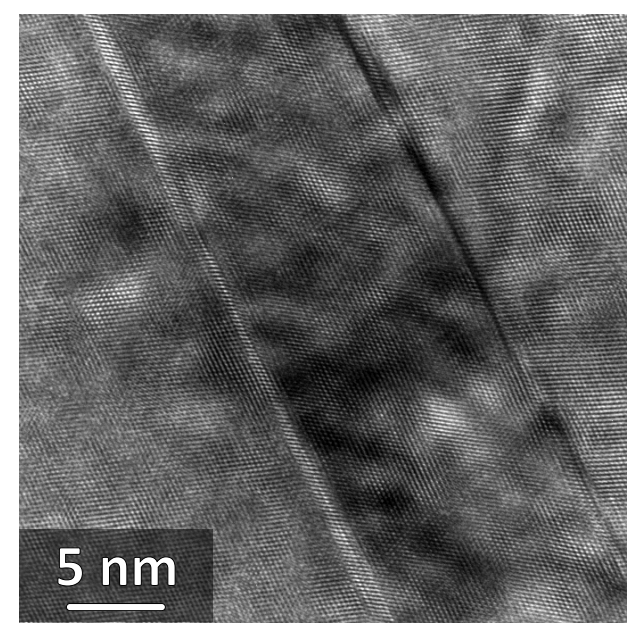

(b)

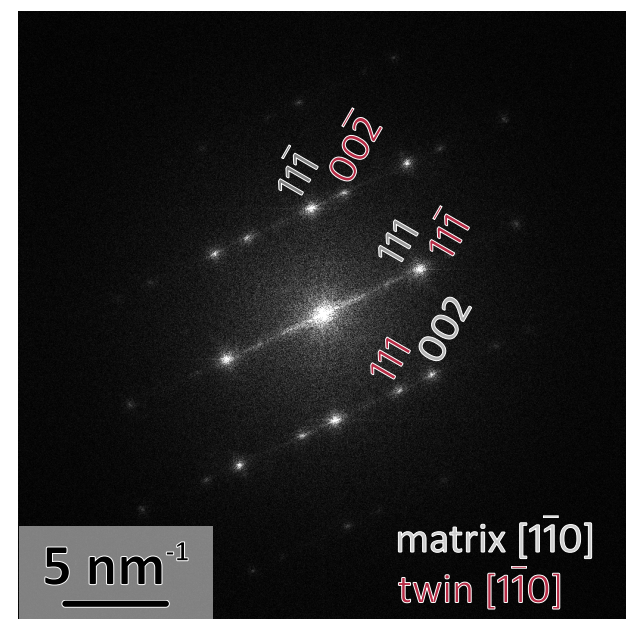

(c)

Figure 7: High-resolution TEM micrograph of the twinned micrustructure with (a) 250kfold and (b) 600k-fold magnification. Subfigure (c) represents a fast Fourier transform across the twin boundary indicated by an arrow in (a); the corresponding zone axis is [1ㅣㅣ. The TEM lamella was cut from the grain shown in Fig. 6(a). 


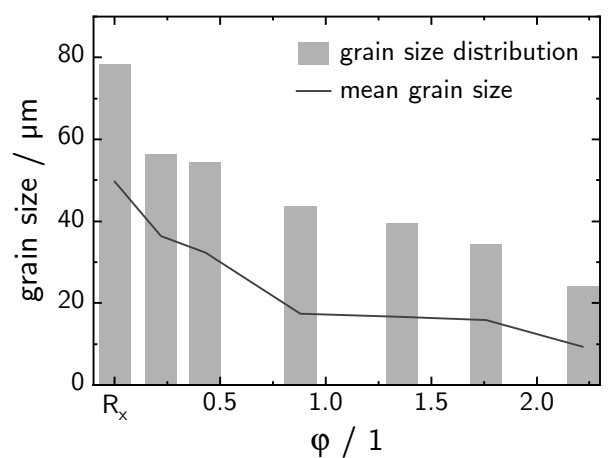

Figure 8: Evolution of the grain size of cross sections during cold work in dependence of the applied logarithmic degree of deformation.

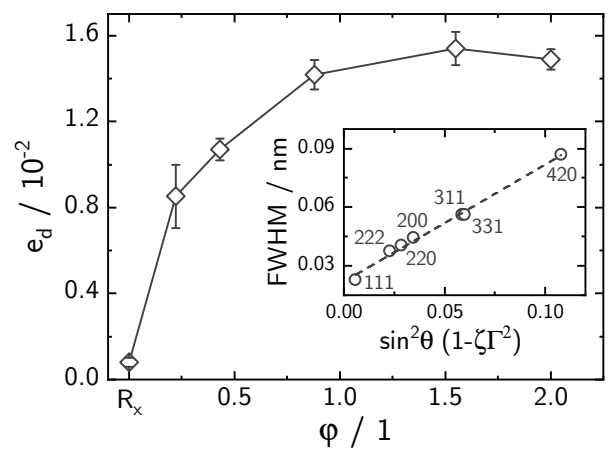

Figure 9: Evolution of the lattice strain during cold work in dependence of the applied degree of deformation determined by Williamson-Hall analysis of XRD diffraction pattern. As example the modified Williamson-Hall plot from the sample with $\varphi=0.43$ is inserted within the diagram. 


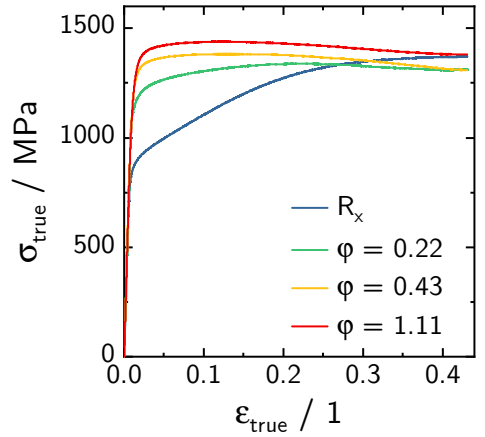

(a)

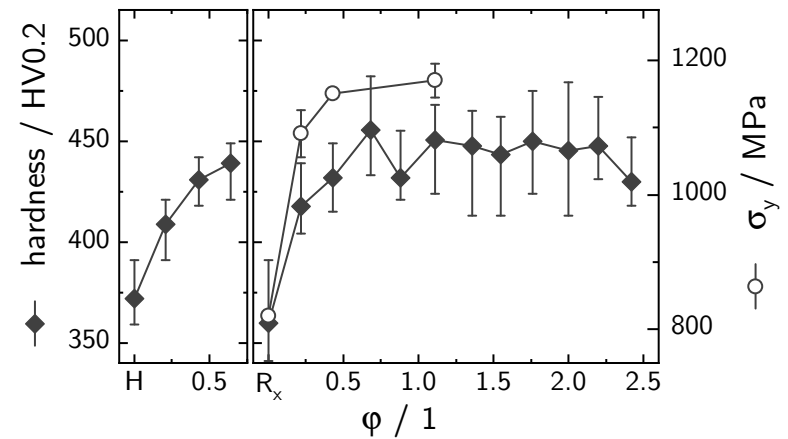

(b)

Figure 10: Mechanical properties of AuCuNiPdPt: (a) true compressive stress-strain curves in the recrystallised $\left(\mathrm{R}_{\mathrm{x}}\right)$ and in various cold worked states as well as (b) the resulting yield strength in comparison to the hardness values after recrystallisation depending on the logarithmic degree of deformation. Hardness values during cold work after homogenisation $(\mathrm{H})$ are also provided.

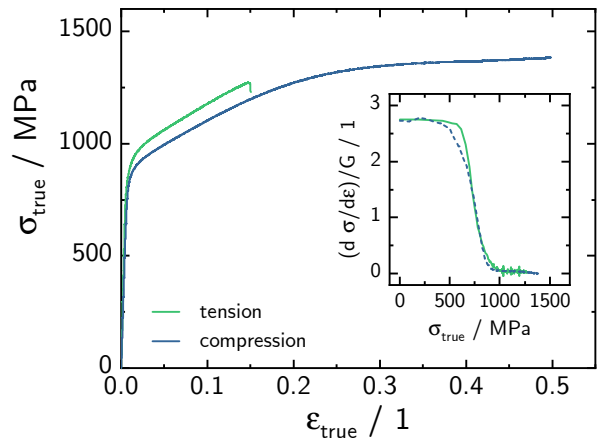

Figure 11: Comparison of compression and tension true stress-strain curves of $\mathrm{AuCu}$ NiPdPt in the recrystallised state. The insert shows the corresponding work hardening rates. 


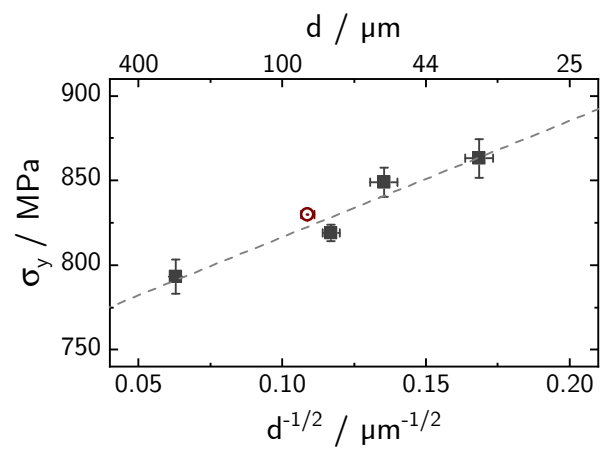

Figure 12: Dependence of the yield strength on the grain size of AuCuNiPdPt. Closed symbols represent compressive data, while the open symbol represents the data from the tensile test. 